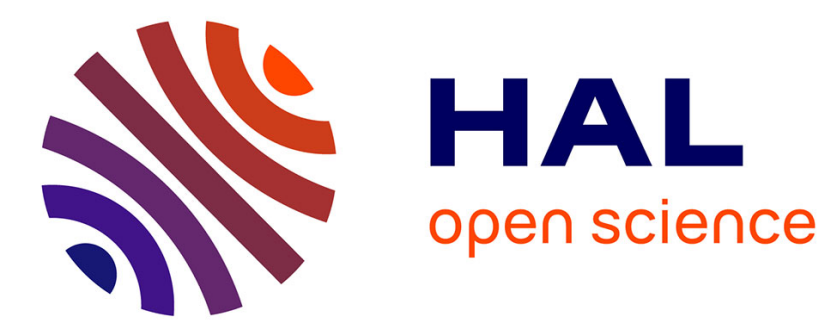

\title{
Sensitivity analysis of transfer functions of laminar flames
}

\author{
Florent Duchaine, F. Boudy, D. Durox, Thierry Poinsot
}

\section{To cite this version:}

Florent Duchaine, F. Boudy, D. Durox, Thierry Poinsot. Sensitivity analysis of transfer functions of laminar flames. Combustion and Flame, 2011, 10.1016/j.combustflame.2011.05.013 . hal-02571551

\section{HAL Id: hal-02571551 \\ https://hal.science/hal-02571551}

Submitted on 20 May 2020

HAL is a multi-disciplinary open access archive for the deposit and dissemination of scientific research documents, whether they are published or not. The documents may come from teaching and research institutions in France or abroad, or from public or private research centers.
L'archive ouverte pluridisciplinaire HAL, est destinée au dépôt et à la diffusion de documents scientifiques de niveau recherche, publiés ou non, émanant des établissements d'enseignement et de recherche français ou étrangers, des laboratoires publics ou privés. 


\title{
Sensitivity analysis of transfer functions of laminar flames
}

\author{
F. Duchaine $e^{* a, b, 1}$, F. Boudy ${ }^{c}$, D. Durox ${ }^{c}$, T. Poinsot ${ }^{a, b}$ \\ ${ }^{a}$ Université de Toulouse; INPT, UPS; IMFT, Allée Camille Soula, F-31400 Toulouse, \\ France \\ ${ }^{b}$ CNRS ; IMFT ; F-31400 Toulouse, France \\ ${ }^{c}$ Laboratoire EM2C, CNRS and Ecole Centrale Paris, 92295 Chatenay-Malabry, France
}

\begin{abstract}
The sensitivity of laminar premixed methane / air flames responses to acoustic forcing is investigated using Direct Numerical Simulation to determine which parameters control their flame transfer function. Five parameters are varied: (1) the flame speed $s_{L},(2)$ the expansion angle of the burnt gases $\alpha$, (3) the inlet air temperature $T_{a},(4)$ the inlet duct temperature $T_{d}$ and (5) the combustor wall temperature $T_{w}$. The delay of the flame transfer function is computed for the axisymetric flames of Boudy et al. [1] and the slot flames of Kornilov et al. [2]. Stationary flames are first computed and compared to experimental data in terms of flame shape and velocity fields. The flames are then forced at different frequencies. Direct Numerical Simulations reproduce the flame transfer functions correctly. The sensitivity analysis of the flame transfer function is done by changing parameters one by one and measuring their effect on the delay. This analysis reveals that the flame speed $s_{L}$ and
\end{abstract}

*Corresponding author. Now at CERFACS. Tel.: (33) (0)5 611930 37; Fax: (33) (0)5 61193000

Email address: florent.duchaine@cerfacs.fr (F. Duchaine) 
the inlet duct temperature $T_{d}$ are the two parameters controlling the flame delay and that any precise computation of the flame transfer function delay must first have proper models for these two quantities.

Key words: Flame Transfer Function, Sensitivity Analysis, Direct Numerical Simulation, Laminar Flames

\section{Introduction}

The prediction of acoustically coupled instabilities has become a major issue in combustion $[3,4]$. Numerous authors have proposed approaches to predict the resonant modes between acoustics and combustion $[5,6,7,8,9$, 10]. In all theories, a crucial ingredient is the flame transfer function (FTF) first introduced by Crocco [11, 12] and Tsien [13]. In its simplest form, the FTF $F(\omega)$ measures the response of the global unsteady reaction rate in the flame $\left(q^{\prime} / \bar{q}\right)$ to an inlet velocity perturbation $\left(u^{\prime} / \bar{u}\right)$ measured at a fixed reference point:

$$
F(\omega)=\frac{q^{\prime} / \bar{q}}{u^{\prime} / \bar{u}}
$$

Altough many of these studies were performed for complex geometry turbulent burners $[14,10,15,16]$, they are usually limited and difficult to extrapolate to other regimes or other geometries because turbulent systems combine the difficulties of acoustic / flame coupling and turbulent flows. To isolate the mechanisms controlling FTF results, some groups have started investigating simpler laminar flames where the validity of acoustic / combustion theories can be tested in the absence of complex turbulent effects $[17,18,19,20]$. Studies dedicated to the FTF of laminar flames in multiple configurations $[21,2,22,23,1]$ are now available, providing both experimental and numer- 
ical methods to obtain FTFs. In these cases, only acoustic perturbations imposed on perfectly premixed flames are investigated. Equivalence ratio fluctuations are out of the scope of the present study.

In all these configurations, the values obtained for the FTFs parameters are a gain $n$ and a phase $\phi$ (or delay $\tau=\phi / \omega$ ), which depend on the forcing frequency $\omega$ and in certain cases on the forcing amplitude (see for example the recent developments on the flame describing function [21]). These parameters are critical to predict stability in acoustic solvers [11, 24, 25, 26]. Small errors on the phase $\phi$ can lead to drastic changes in stability so that the question of uncertainties in measurement and simulation of FTF becomes an interesting issue. When computing the FTF of a flame, being able to evaluate the sensitivity of the results to modeling parameters is a critical question. For example, Kaess et al. [27] computed the FTF of a laminar flame and concluded that an accurate computation was impossible without the knowledge of the temperature of the stabilizing plate. More generally, many other input parameters of a FTF simulation may affect results and it is important to identify their relative importance. Experimentally, the same question arises: if FTF measurements depend critically on parameters which are not measured with accuracy, results will be useless. For example, the temperature of the plate on which flame are stabilized is rarely measured with precision but it could have a strong effect on the FTF.

A good solution to guess which parameters can modify FTFs is to start from theoretical models for the delay $\tau[17,19,14]$. The global heat release rate $q(t)$ of a flame is written as $[7,17]$ :

$$
q(t)=\int_{s} \rho_{u} s_{L} \Delta q d A
$$


where the integral is performed over the flame surface, $\rho_{u}$ is the unburnt gas density, $s_{L}$ the flame speed and $\Delta q$ is the heat release per unit mass of mixture. From Eq. 2, fluctuations in the density $\rho_{u}$, the flame speed $s_{L}$, the heat of reaction $\Delta q$ and in the flame surface $A$ contribute to heat release oscillations $q^{\prime} / \bar{q}$. Considering a perfectly premixed flow with a constant density and neglecting the effect of the stretch due to flame wrinkling on flame speed [28], the FTF can be expressed in terms of two dimensionless parameters $\omega^{*}$ and $s_{L}^{*}[7,17,19,14]$ :

$$
F(\omega)=\frac{q^{\prime} / \bar{q}}{u^{\prime} / \bar{u}}=F\left(\omega^{*}, s_{L}^{*}\right)=F\left(\frac{\omega H_{f}}{V_{e}}, \frac{s_{L}}{V_{e}}\right)
$$

where $V_{e}$ is the convective velocity at the burner inlet and $H_{f}$ is the flame height. It is generally complex to express directly the fluctuation of the heat release as a function of the fluctuating velocity. Nevertheless, since it is observed that the phase $\phi$ increases regularly with $\omega^{*}$, it is possible to describe $\phi$ as a time lag $\tau=\phi / \omega$. The simplest way to evaluate $\tau$ is to express it as the mean time necessary for a velocity perturbation to be convected from the exit plane to the effective position of concentrated heat release $[17,14]$ :

$$
\tau=\frac{H_{f}}{\beta V_{e}}
$$

where $\beta$ is a coefficient depending on the configuration. Values of $\beta$ ranging from 1 to 3 are typically measured. Since the flame height depends on the flame speed $s_{L}$ and on the convective velocity $V_{e}$, Eq. 4 suggests that $\tau$ changes only with $s_{L}$ and $V_{e}$, hence that kinetic parameters (controlling $s_{L}$ ) but also temperatures of gas and walls (controlling $V_{e}$ ) must be important input data for $\tau$. 
In this paper, FTFs of laminar premixed flames were computed using direct numerical simulation (DNS) to evaluate the influence of five critical input parameters (Fig. 1): (1) the flame speed $s_{L},(2)$ the shape of the domain characterized by its expansion angle $\alpha,(3)$ the inlet air temperature $T_{a}$, (4) the inlet duct temperature $T_{d}$ and (5) the combustor wall temperature $T_{w}$.

All these parameters have a direct effect on the FTF delay $\tau$ (or phase $\phi)$. The flame speed $s_{L}$ obviously controls the flame length and therefore the delay of the flame to react to velocity changes. The shape of the domain determines the expansion of the burnt gases and the flow velocity, thereby also changing the FTF delay: here it is supposed to have a conical shape of angle $\alpha$. Many experiments (and computations) are designed to perfectly match periodic arrays of flame $[21,2]$ where $\alpha$ should be zero. Note that the confinement of the flames comes from the proximity of neighboring flames and not from a closed burner. In practice however, these flames are only partially confined: the gases produced by each individual flame can expand both in the axial and transverse directions. This can be accounted for in the DNS by using an expanding computation and values of $\alpha$ up to ten degrees are commonly observed experimentally. The inlet air temperature $T_{a}$ affects both the gas velocity and the flame speed whereas the inlet duct temperature $T_{d}$ changes the temperature and velocity profiles at the burner inlet. The combustor walls temperature $T_{w}$ determines the lift-off of the flame and can also control the FTF delay. Obviously, other uncertainties and phenomena can affect the FTF as radiation heat losses, geometric imperfections, inlet velocity profiles (steady and forcing parts), flame to flame interactions, threedimensional effects or position of the reference point for the velocity $u^{\prime} / \bar{u}$ 
measurement. Nevertheless, the study is restricted to these five parameters which are difficult to determine precisely, have an important impact on FTF, and are easily manageable with a CFD solver.

The objective of this work is to determine the sensitivity of the FTF to these five parameters. This identification will be done using simple differentiation methods (i.e. changing only one parameter and measuring its effect on the FTF delay). The exercise will be performed on two recent laminar flame experiments (Fig. 2) for which extensive sets of experimental results are available: the experiment of Boudy et al. [1] corresponds to 49 conical flames stabilized on a perforated plate while the configuration of Kornilov et al. [2] corresponds to an array of 12 slot flames.

The paper is organized as follows. First the Boudy et al. and Kornilov et al. experimental facilities are presented. The numerical methodology used to predict the FTFs is then described. Uncertainty sources in FTF phase determination are identified and the methodology for the sensitivity analysis is exposed. Finally, results on steady and forced flames are analyzed.

\section{Experimental facilities}

One method to study FTF is to take the flame out of its combustion chamber and pulsate it. This has two advantages: (1) optical diagnostics (usually radical emission) are easier and (2) the absence of the combustion chamber limits the occurrence of self-excited modes. It is generally assumed that the FTF does not change when the chamber is removed even though the confinement of the flame obviously changes. In this paper, two recent unconfined laminar experiments are used: the first one is referred in the following of 
the paper as the Boudy case [1] and the second one as the Kornilov case [2]. Both experiments use methane as fuel and operate at atmospheric conditions $(p=1 \mathrm{~atm}$ and $T=293 \mathrm{~K})$ and the combustion zones are unconfined. For the cases used here, the equivalence ratio for the Boudy experiment is 1.03 while it is 0.8 for the Kornilov case. The range of frequencies for FTF measures is up to $1600 \mathrm{~Hz}$ for the Boudy case and $600 \mathrm{~Hz}$ for the Kornilov one. This section provides descriptions of these two experiments. Details concerning measurement techniques and experimental determination of FTF can be found in $[1,2]$.

\subsection{Boudy experiment setup}

The experimental setup of Boudy et al. [1] is sketched in Fig. 2. The two main components of the burner are the feeding manifold and a perforated plate which delivers the premixed streams and anchors the flames. The perforated plate located at the top of the feeding manifold, anchors 49 small laminar conical flames. It has a thickness of $3 \mathrm{~mm}$ and a diameter of $30 \mathrm{~mm}$. The plate is made of stainless steel, and comprises 49 holes of diameter $2 r_{p}=$ $2 \mathrm{~mm}$ placed on a $3 \mathrm{~mm}$ square mesh. An inlet velocity of $v_{a}=1.09 \mathrm{~ms}^{-1}$ in the feeding manifold is used to stabilize the flames, leading to a bulk velocity in the holes of about $V=3.11 \mathrm{~ms}^{-1}$. The temperature of the plate is evaluated experimentally as $450 \pm 20 \mathrm{~K}$ for steady combustion.

\subsection{Kornilov experiment setup}

The Kornilov et al. [2] experiment consists of a vessel with a flat perforated disk of $1 \mathrm{~mm}$ thickness inserted on top of it (Fig. 2). The disk contains 8 rectangular $12 \times 2 \mathrm{~mm}$ slits separated by $3 \mathrm{~mm}$. An inlet velocity 
of $v_{a}=0.4 \mathrm{~ms}^{-1}$ below the plate is used to stabilize the flames, leading to a bulk velocity in the slits of about $V=1 \mathrm{~ms}^{-1}$. The burner plate temperature is measured by a K-type thermocouple embedded in the center of the burner plate. This temperature is not known precisely and varies between 373 and $423 \mathrm{~K}$ during steady combustion.

\section{Numerical approach}

\subsection{Fluid solver}

The fluid solver simulates the fully compressible multi-species NavierStokes equations on unstructured grids. Convective terms are discretized using a third-order accurate two-step Taylor-Galerkin scheme [29]. It provides high spectral resolution and both low numerical diffusion and dispersion, which is particularly adequate for requirements of DNS applications [30]. Diffusive terms are treated with the classical Galerkin method [29].

For both configurations, a single steady laminar flame is first computed using DNS and a two-step chemical scheme (2S-CM2) for methane / air combustion [10]. Present state-of-the-art DNS codes [31, 32, 33] would allow flame computations with full chemistry schemes such as GRI-Mech but it was considered as not necessary for the present work because 2S-CM2 provides essentially the same results in these simple flames. Moreover, most DNS codes able to handle full chemical scheme cannot handle complex geometries as needed for the Boudy or Kornilov cases. The two-step scheme 2S-CM2 takes into account six species $\left(\mathrm{CH}_{4}, \mathrm{O}_{2}, \mathrm{CO}_{2}, \mathrm{CO}, \mathrm{H}_{2} \mathrm{O}\right.$ and $\left.\mathrm{N}_{2}\right)$ and two reactions:

$$
\mathrm{CH}_{4}+\frac{3}{2} \mathrm{O}_{2} \longrightarrow \mathrm{CO}+2 \mathrm{H}_{2} \mathrm{O}
$$




$$
\mathrm{CO}+\frac{1}{2} \mathrm{O}_{2} \longleftrightarrow \mathrm{CO}_{2}
$$

The first reaction (5) is irreversible whereas the second one (6) is reversible and leads to an equilibrium between $\mathrm{CO}$ and $\mathrm{CO}_{2}$ in the burnt gases. The rates of reaction (5) and (6) are respectively given by:

$$
\begin{aligned}
& q_{1}=A_{1}\left(\frac{\rho Y_{C H_{4}}}{W_{C H_{4}}}\right)^{n_{1}^{C H_{4}}}\left(\frac{\rho Y_{O_{2}}}{W_{O_{2}}}\right)^{n_{1}^{O_{2}}} \exp \left(-\frac{E_{a 1}}{R T}\right) \\
& q_{2}=A_{2}\left[\left(\frac{\rho Y_{C O}}{W_{C O}}\right)^{n_{2}^{C O}}\left(\frac{\rho Y_{O_{2}}}{W_{O_{2}}}\right)^{n_{2}^{O_{2}}}-\left(\frac{\rho Y_{C O_{2}}}{W_{C O_{2}}}\right)^{n_{2}^{C O_{2}}}\right] \exp \left(-\frac{E_{a 2}}{R T}\right)
\end{aligned}
$$

where the parameters are provided in Table 1 . This scheme is fitted on the

GRI-Mech V3 [34] to ensure that the two-step and GRI mechanisms produce the same flame speeds and maximum temperatures for laminar premixed onedimensional flames for equivalence ratio ranging between $\phi=0.4$ and 1.2. Note that the Lewis numbers of methane and oxygen remain close to unity so that differential diffusion effects, which are accounted for in the DNS, remain limited. The transport coefficients used for 2S-CM2 are obtained from a CHEMKIN computation in the fresh gases (Table 2). The Prandtl number is set to 0.68 .

\subsection{Configurations}

When multiple flames are used (49 for the Boudy case and 12 for the Kornilov one), the usual approach is to compute only one flame using periodic boundary conditions [27]. The Boudy case is a three-dimensional problem while the Kornilov can be seen as a two-dimensional one. As a consequence, the three-dimensional domain for the Boudy configuration includes one hole of the perforated plate and periodic conditions are applied on lateral sides 
both in the plenum and in the combustion zone. On Figure 3, model (a) represents an ideal case where the flame is surrounded by an infinity of identical flames. In order to reduce the computational time requested by the sensitivity analysis, a second model for the Boudy case was investigated: model (b) (Fig. 3) is a two dimensional axi-symetric configuration. The lateral side in the combustion zone is an adiabatic slip wall. The radius $r_{c}$ of the cylindrical combustion zone is fixed to match the surface of the flow passage $s$ : $r_{c}=\sqrt{s^{2} / \pi}$. Inlet velocity and temperature profiles of fresh methane / air mixture are extracted from the 3D simulation and imposed at the hole entrance. As numerical results obtained with models (a) and (b) are the same, only results obtained with the axi-symetric geometries are presented in this paper. The Kornilov model (Fig. 3) is a two-dimensional domain containing only one half flame. Symmetry is enforced on the symmetry plane of the flame, and adiabatic slip walls on other sides. For both the Boudy and Kornilov cases, it has been checked for a zero confinement angle that symmetry and adiabatic slip wall on lateral boundaries give the same results.

The meshes are refined near the flame front as well as in the feeding ducts in order to resolve the flames, capture the aerodynamics as well as heat transfer at the walls. Convergence in terms of mesh resolution has been reached with more than 10 cells in the flame fronts, leading to meshes containing about 81100 nodes and 80400 cells for the Boudy case and 34300 nodes and 64900 cells for the Kornilov configuration.

\subsection{Boundary conditions and Flame Transfer Function determination}

For both configurations, the inlet and outlet boundary conditions are non-reflecting boundary conditions imposed with the Navier-Stokes Charac- 
teristic Boundary Condition (NSCBC) formalism [35]. The NSCBC method is used to control the reflection coefficient at the boundaries and to avoid the propagation of nonphysical modes. The plate walls are treated as isothermal walls. The reference wall temperatures are $430 \mathrm{~K}$ for the Boudy configuration and $373 \mathrm{~K}$ for the Kornilov case.

FTF are determined through pure tone excitations by measuring the flame response at different frequencies. A steady flame is first obtained as an initial condition. Harmonic forcing is then applied at the inlet using the inlet wave modulation method [36]. This technique consists in modulating the acoustic wave entering the domain while letting the wave leaving the domain propagate without reflection. For both cases, a perturbation amplitude $v_{a}^{\prime} / \bar{v}_{a}$ smaller than $10 \%$ was chosen to avoid non linear flame responses.

According to the definition of thermo-acoustic transfer function (Eq. 1), the phase of the FTF can be reconstructed from the measured time series of the relative flow velocity perturbation $u^{\prime} / \bar{u}$ at a reference point and the relative heat release rate perturbation $q^{\prime} / \bar{q}$. The phase difference between both signals is determined using cross-correlation analysis. As far as the Boudy case is considered, the reference point for the velocity measurement is located in the combustion zone $0.7 \mathrm{~mm}$ over the plate. Concerning the Kornilov setup, the reference probe is placed in the feeding manifold, at the inlet of the CFD configuration. These reference points are those used in the experiments. The perturbed heat release $q^{\prime} / \bar{q}$ time evolution is obtained by spatially averaging the combustion source term. 


\subsection{Identification of uncertainty sources for phase determination}

The first parameter which can affect the FTF is the flame speed $s_{L}$. Flame speeds are difficult to determine experimentally or numerically with high precision $[37,38,39]$ particularly when increasing the temperature of the fresh mixture [40]: being able to obtain the laminar flame speeds of hydrocarbon / air flames within a 2 or $3 \mathrm{~cm} / \mathrm{s}$ error margin remains a challenge. Determining the effect of such an uncertainty on the FTF result is needed: the flame speed $s_{L}$ obviously controls the flame length and can modify the FTF delay. In the present work, the variation of $s_{L}$ is obtained by changing the pre-exponential constant $A_{1}$ in Eq. 7.

The second source of uncertainty is the confinement. The Boudy and Kornilov experiments are designed to match perfectly periodic arrays of flame. However, Fig. 4 shows that expansion takes place. In practice, these flames are only partially confined: the gases produced by each individual flame can expand both in the axial and lateral directions. Flame confinement acts on the velocity distribution and thus on the flame length and on the propagation speed of velocity perturbations, thereby changing also the FTF delay. The shape of the DNS domain determines the expansion of the burnt gases and the flow velocity. Flame confinement effects are accounted for in the DNS by using an expanding computation domain with a non-zero expansion angle $\alpha$ (Fig. 3).

Although it is usually well controlled in experiments, the third uncertain input of the computation is the inlet methane / air mixture temperature $T_{a}$. The inlet temperature $T_{a}$ affects both the gas velocity and the flame speed $s_{L}$. 
The last two parameters are linked to the temperature of the anchoring plate. The temperature of the combustor walls is difficult to measure or to estimate numerically. As underlined on Fig. 1, the combustor wall temperature can be divided into two contributions: (1) the inlet duct temperature $T_{d}$ controls the gas temperature in the hole (or in the slit) by convection and thus velocity profiles at the burner inlet as well as the local flame speed $s_{L}$ along the flame front. (2) the combustor walls temperature $T_{w}$ determines the lift-off of the flame and thus can also affect the FTF delay. Note that the temperatures $T_{d}$ and $T_{w}$ are correlated but are analyzed here separately to understand their respective roles. It is worth mentioning that DNS solvers allow to control efficiently and independently the inlet temperature $T_{a}$, the inlet duct temperature $T_{d}$ and the combustor walls temperature $T_{w}$, something which is almost impossible experimentally.

\subsection{Methodology of the sensitivity analysis}

The sensitivity analysis is done using simple linear differentiation methods by changing one parameter only and measuring its effect on the FTF delay. Tables 3 and 4 summarize the DNS used to estimate the sensitivity of FTF phase $\phi$. The extreme values retained for the parameters match their estimated uncertainty. For each set of parameters, a steady state is first computed leading to cases called $B_{1}$ to $B_{10}$ for the Boudy case and $K_{1}$ to $K_{10}$ for the Kornilov configuration. Then, all $B_{i}$ and $K_{i}$ are pulsated at several frequencies [36]. Finally, for each frequency, sensitivities are obtained from differentiations formula given in Tab. 5. 


\section{Results}

\subsection{Validation of steady flames}

Figure 5 displays the reaction rate fields obtained by DNS for the steady flames of Boudy (case $B_{1}$ ) and Kornilov (case $K_{1}$ ) and compares them to experimental direct visualization without filter of the Boudy flame and chemiluminescence of $\mathrm{OH}^{*}$ for the Kornilov flame. For these cases, both flames are slightly lifted and their height matches experimental data reasonably well. The axial velocity field as well as the temperature field of the $B_{1}$ and $K_{1}$ steady flames are presented on Fig. 6. The contraction of the flow in the plenum creates a transverse velocity in the holes. As evidenced in the experiments [2], a recirculation zone is observed in the flame holding region of both flames (isoline of null axial velocity on Fig. 6). The heating of the gas inside the hole (case $B_{1}$ ) and the slit (case $K_{1}$ ) leads to a non homogeneous temperature profile of the gases at the flame base (Fig. 6): gases close to the inlet duct walls are heated and enter in the combustion zone at higher temperature. Furthermore the mean temperature of the injected gases in the combustion zone is higher than the temperature of the methane / air mixture in the plenum (typically $50 \mathrm{~K}$ ).

Figure 7 presents the axial velocity profile on the flame axis for the $B_{1}$ and $K_{1}$ steady cases compared to experiments. The flow contraction beneath the perforation leads to a gradual increase of the vertical velocity as well as a tangential velocity. Inside the flame, the axial velocity remains almost constant, weakly decreasing in both experimental configurations toward the flame front. Then, a rapid acceleration of the flow due to gas expansion occurs at the flame tip. In both configurations, the profile in the vicinity 
of the plate is well reproduced. Concerning the Kornilov case, the agreement between the DNS and the measurement is very good in a large region. Kornilov et al. explain the differences observed upstream of the plate and downstream of the flame by three-dimensional effects: flow contraction in the plenum and expansion in the combustion zone occur in the direction perpendicular to the measured section plane. As a result, the velocity profile is not flat in the experimental plenum while a flat profile in imposed in the DNS. The agreement for the Boudy case is less convincing. Nevertheless, Fig. 10-(b) shows that confinement effects control the shape of the velocity profile in this flame. For both cases, Fig. 7 shows that the velocity on the center line of the flow passage is not fully developed: the plate thicknesses of the two configurations are not sufficient to establish a parabolic laminar profile in the pipes. As a consequence, reproducing the correct geometry in the DNS is important to capture the velocity and temperature profiles at the combustor inlet. The radial profile of axial velocity at the burner inlet for case $B_{1}$ plotted on Fig. 8 shows a good agreement between DNS and experiments. No experimental information concerning this profile for the Kornilov configuration is available.

\subsection{Baseline Flame Transfer Functions}

Experimental and numerical phases $\phi$ and gains of FTF for the Boudy $B_{1}$ and Kornilov $K_{1}$ configurations are compared on Fig. 9. The phase evolves with frequency in a quasi-linear fashion below $600 \mathrm{~Hz}$ indicating that the process includes a constant time delay. After $600 \mathrm{~Hz}$, the simulation indicates that the phase of the Kornilov flame saturates. The correspondence for the Kornilov flame is very good while the delay obtained numerically for 
the Boudy flame is slightly shorter than observed in the experiments. Note however that results can be much better for other sets of parameters as shown in section 4.4 by the high sensitivity of delays to input parameters. Our objective was not to fit experimental data by tuning the parameters but to determine which of these parameters was important as done in the next sections. The analytical estimation given by Eq. 4 is also plotted on Fig. 9. The convective velocity $V_{e}$ and the flame height $H_{f}$ are deduced from the computations $B_{1}$ and $K_{1}$ : they are taken as the bulk velocity at the perforation exit $\bar{V}_{e}$ and the distance between the plate and the flame tip, respectively. The parameter $\beta$ is then chosen to fit the data. Due to the geometrical differences of the flames, Fig. 9 shows that each configuration requires a distinct value of $\beta$ : $\beta=2$ for the Boudy case and $\beta=1$ for the Kornilov one.

Concerning the gain, the simulations of both cases reproduce the lowpass behavior of the flame seen experimentally. Moreover, the overshoot of the FTF gain above 1 at $400 \mathrm{~Hz}$ for the Boudy case and at $100 \mathrm{~Hz}$ for the Kornilov case is also recovered by the DNS.

\subsection{Effect of uncertain inputs on steady flames}

The effect of the five input parameters (1) flame speed $s_{L},(2)$ confinement $\alpha$, (3) inlet mixture temperature $T_{a}$, (4) duct temperature $T_{d}$ and (5) combustor wall temperature $T_{w}$ on the Boudy and Kornilov steady flames is investigated through integral values presented in Tab. 6 (Boudy case) and 7 (Kornilov case) as well as with velocity profiles on the flame axis (Fig. 10). As the qualitative effects of inputs are almost the same for both Boudy and Kornilov flames, Fig. 10 displays only results for the Boudy configuration. 
The quantities of interest in Tab. 6 and 7 are:

- the bulk velocity at the perforation exit $\bar{V}_{e}$,

- the maximum of the exit perforation velocity profile $V_{e}^{M}$,

- the flame surface $S_{F}$, taken as the surface of the iso-temperature $T=$ $1700 \mathrm{~K}$

- the flame lift-off $L_{F}$, estimated by the axial distance between combustor wall and the closest part of the iso-temperature $T=1700 \mathrm{~K}$,

- the mean flame speed $\overline{s_{L}}$, approximated by:

$$
\overline{s_{L}}=\frac{\overline{\rho_{e} V_{e}} S_{H}}{\bar{\rho}_{e} S_{F}}
$$

where $\bar{\rho}_{e}$ and $\bar{\rho}_{e} V_{e}$ are the mean density and mean mass flux at the perforation exit, respectively. $S_{H}$ is the perforation surface.

- the mean temperature at the hole exit $\bar{T}_{e}$.

Modifying the flame speed $s_{L}$ affects only the combustion zone. Velocity and temperature profiles in the hole as well as in the flame axis are not affected. As expected, a modification of $s_{L}$ impacts directly the mean flame speed $\overline{s_{L}}$. Moreover, increasing the flame speed leads to a shorter flame (decrease of $S_{F}$ ) located closer to the flame holder (decrease of $L_{F}$ ).

The main effect of flame confinement is to modify the axial velocity profile on the flame axis. Increasing the confinement angle $\alpha$ reduces the axial velocity by allowing a transverse flow rate leading to a flame which is slightly more compact and closer to the plate. Figure 10-(b) shows that a confinement 
with $\alpha=10^{\circ}$ leads to a very good prediction of the experimental velocity profile for the Boudy case, confirming that flow expansion takes place in this configuration.

Modifying the inlet methane / air mixture temperature $T_{a}$ leads to a change of the mean consumption speed $\overline{s_{L}}$ : as $T_{a}$ increases, $\overline{s_{L}}$ increases, thus leading to a shorter flame located nearer the plate (flame lift-off $L_{F}$ decreases, Tab. 6 and 7).

The inlet duct temperature $T_{d}$ controls the intensity of the convective heat transfer, thus controlling the temperature elevation in the pipe $\Delta T_{c}$. As a result, increasing $T_{d}$ leads to a greater mean temperature at the perforation outlet, thus to an increase of the flame speed. An increase of the temperature elevation $\Delta T_{c}$ causes an acceleration of the flow in the perforation (illustrated on Fig. 10-d). As a consequence, convective heat transfer in the duct has two competitive effects on the flame length: the elevation of temperature induces (1) an higher flame speed, shortening the flame and (2) an acceleration of the fresh stream inducing a longer flame.

The more intuitive effect of the combustor wall temperature $T_{w}$ is to control the flame lift-off $L_{F}$. As expected, Tab. 6 and 7 shows that the flame lift-off is reduced by increasing the combustor wall temperature. Due to the recirculation of hot gases at the flame base, the mean inlet temperature $\bar{T}_{e}$ is slightly higher when $T_{w}$ increases. Therefore, higher $T_{w}$ implies higher mean flame speed $\overline{s_{L}}$ leading to shorter flames.

The five parameters (the flame speed $s_{L}$, the expansion angle of the burnt gases $\alpha$, the inlet air temperature $T_{a}$, the inlet duct temperature $T_{d}$ and the combustor wall temperature $T_{w}$ ) have an important impact on both the 
mean flame consumption speed $\overline{s_{l}}$ as well as on the fresh stream velocity entering in the combustion zone, thus the flame length. Equation 4 shows that models developed in the field of FTF always include these quantities so that uncertainties on the parameters lead to error in the estimation of FTF. The next section focuses on the quantification of these errors.

\subsection{Sensitivity of Flame Transfer Functions}

The computations of FTF were done for the $B_{1}$ to $B_{10}$ set of parameters for the Boudy flame and $K_{1}$ to $K_{10}$ for the Kornilov flame to obtain values of the sensitivity of the phase $\phi$ versus each parameter for different forcing frequencies. The sensitivity of the phase to a parameter $P$ at a pulsation $\omega$ is defined by (Tab. 5):

$$
S(\omega, P)=\frac{\partial \phi(\omega)}{\partial P}, P \in\left[s_{L}, \alpha, T_{a}, T_{d}, T_{w}\right]
$$

Sensitivity results are given in Tab. 8 at a fixed forcing frequency of 500 Hz. Input parameters induce the same variation signs for both the Boudy and the Kornilov cases: on one hand, increasing the flame speed $s_{L}$, the inlet methane / air mixture temperature $T_{a}$, the duct temperature $T_{d}$ or the combustor wall temperature $T_{w}$ leads to a decrease of the FTF phase $\phi$. On the other hand, allowing hot gases expansion by increasing the angle $\alpha$ induces a longer delay.

If typical error margins are known for each parameter, Tab. 8 allows to identify critical parameters to compute FTF delays. For flame speeds $\left(s_{L}\right)$, typical errors are of the order of $\Delta s_{L}=2 \mathrm{~cm} \mathrm{~s}^{-1}$ even with the best present chemical schemes. The expansion angles $(\alpha)$ can be approximately measured from experiments and are of the order of $\Delta \alpha=4$ degrees. The gas inlet 
temperature $T_{a}$ is generally controlled accurately, typically within $\Delta T_{a}=2$ $\mathrm{K}$. The duct temperature $T_{d}$ is very difficult to evaluate and errors of the order of $\Delta T_{d}=50 \mathrm{~K}$ must be expected. Similarly the wall temperatures $T_{w}$ are usually not known within a $\Delta T_{w}=50 \mathrm{~K}$ margin.

Gathering these uncertainties with the sensitivities of Tab. 8 leads to Tab. 9 which gives the error induced on the phase $\phi$ by the uncertainty existing on each of the five parameters. Absolute error is defined by:

$$
E_{A}(\omega, P)=S(\omega, P) \Delta P, P \in\left[s_{L}, \alpha, T_{a}, T_{d}, T_{w}\right]
$$

and relative error by:

$$
E_{R}(\omega, P)=\frac{S(\omega, P) \Delta P}{\phi_{1}}, P \in\left[s_{L}, \alpha, T_{a}, T_{d}, T_{w}\right]
$$

where $\phi_{1}$ is the phase of the reference cases $B_{1}$ or $K_{1}$. First, absolute errors are all larger for the Kornilov experiment than for the Boudy case. Nevertheless, as the values of the delay are smaller for the Boudy case (Fig. 9), the relative errors are of the same order for the two cases. In other words, both experiments are almost equally sensitive to input parameters. Moreover, certain parameters such as the combustor wall temperature $T_{w}$ (which control the flame lift-off) have no influence at all in both cases and it is not worth spending time trying to determine them with precision. Flow expansion $(\alpha)$ also has a limited effect. The phase has a rather high sensitivity to inlet temperature (Tab. 8) but it is usually well known, leading to small errors on the FTF phase.

Figure 11 shows that the dominant role of the flame speed $s_{L}$ and of the duct temperature $T_{d}$ is obtained on the whole range of frequency $100 \mathrm{~Hz}$ to 
$500 \mathrm{~Hz}$. Beyond $600 \mathrm{~Hz}$, the effect of the input parameters is largely reduced because of phase saturation observed on Fig. 9.

To sum up, two parameters play a significant role:

- the flame speed $s_{L}$ has a direct effect on the delay. Unfortunately, this is typically a quantity that is not well known and difficult to specify with precision. In the present computation, $s_{L}$ is not specified directly because finite rate chemistry is used but it is a direct function of the preexponential constants used in the chemistry description. The main problem here is that experiments do not allow flame speed measurements within a $2 \mathrm{~cm} \mathrm{~s}^{-1}$ range for hydrocarbon flames so that it is difficult to adjust kinetic models for DNS.

- the duct wall temperature $T_{d}$ induces significant errors on the FTF phase $\phi$ because it is difficult to evaluate precisely. For both cases, it is essential to know the wall temperature of the inlet duct to predict the phase correctly. Moreover for the present cases, the duct temperature was assumed to be the same everywhere: in practice, it could also vary with spatial position.

The importance of the duct wall temperature comes from multiple facts. The premixed gas passing through the inlet duct is heated significantly by the hot walls: the gas velocity increases (because of the reduced density) and the local flame velocity also increases. These two factors modify the velocity field and the flame response to pulsations.

From the previous analysis, the mean flame speed $\overline{s_{L}}$ appears to be the critical parameter controlling the response of the flame. Indeed, four of 
the five input parameters of the sensitivity analysis also act indirectly on this quantity. Considering that $H_{f} \overline{s_{L}} \approx r_{p} \overline{V_{e}}$ [14], the reduced pulsation $\omega^{*}$ introduced in Eq. 3 becomes:

$$
\omega^{*} \approx \frac{\omega r_{p}}{\overline{s_{L}}}
$$

where $2 r_{p}$ is the diameter of the holes in the Boudy case and the width of the slit for the Kornilov case. With the same approximation, Eq. 4 can be rewritten as:

$$
\phi \approx \frac{\omega r_{p}}{\beta \overline{s_{L}}} \approx \frac{\omega^{*}}{\beta}
$$

Figure 12-a displays the phase $\phi$ of the $K_{1}$ to $K_{10}$ Kornilov flames forced at $200 \mathrm{~Hz}$ as a function of $\omega^{*}$ for all runs of Tab. 4. It confirms that the phase is proportional to the reduced pulsation, which is only controlled by $\overline{s_{L}}$ as the frequency is fixed. A linear increase of the phase with the reduced pulsation is observed, except for the flames $K_{9}$ and $K_{10}$. These flames correspond to a variation in the confinement angle $\alpha$ which does not affect the mean flame speed $\overline{s_{L}}$. Figure 12-b shows that a similar behavior is observed for all frequencies investigated in this work. Hence, the phase of the FTF is controlled by the reduced frequency $[7,17,19,14]$ which is affected by the uncertainties on $s_{L}, T_{a}, T_{d}$ and $T_{w}$. As a consequence, the knowledge of the steady flame height $H_{f}$, mean consumption speed $\overline{s_{L}}$ and mean velocity $\overline{V_{e}}$ allows a good estimation of the FTF phase of this type of laminar flames.

\section{Conclusions}

Flame Transfer Functions (FTFs) measure the response of flames submitted to acoustic forcing. Their determination is critical to predict the stability 
of combustors. The present work has focused on the determination of the sensitivity of FTF to five important sources of uncertainty on two laminar premixed flames: (1) the flame speed $s_{L},(2)$ the shape of the domain characterized by its expansion angle $\alpha,(3)$ the inlet air temperature $T_{a},(4)$ the inlet duct temperature $T_{d}$ and (5) the combustor wall temperature $T_{w}$. Results show that these five modeling parameters directly impact velocity profiles and laminar flame speeds of steady configurations and thus the FTF phases. Nevertheless, due to associated typical error margins, two parameters play a dominant role in the FTF phase error calculation:

- the flame speed $s_{L}$ has a direct effect on the delay: increasing $s_{L}$ leads to decrease the FTF phase. Unfortunately, this is typically a quantity which is not well known and difficult to specify with precision even when using the most advanced flame solvers. In this field, research on flame dynamics is conditioned by progress in chemical kinetics.

- the duct wall temperature $T_{d}$ induces significant errors on the FTF phase: an increase in the duct wall temperature induces an acceleration of the fresh mixture at the burner inlet as well as an increase of the local flame speed leading to a decrease of the FTF delay. Knowing the wall temperature of the inlet duct is needed to predict the phase correctly. A direct implication of this result is that coupled computations of flame and heat transfer through the stabilization plate are needed to obtain $T_{d}$ and be able to predict FTFs in such configurations. 


\section{Acknowledgments}

The authors gratefully acknowledge the "Centre Informatique National de l'Enseignement Supérieur" (CINES) as well as the "Centre de Calcul Recherche et Technologie" (CCRT) located in France for access to their computing facilities under the allocation 2010026319 made by "Grand Equipement National de Calcul Intensif" (GENCI). Laurent Selle from IMFT and Viktor Kornilov from TUE are gratefully acknowledged for the interactions and fruitfull exchanges. Part of this work was performed at the 2010 Stanford CTR Summer Program.

\section{References}

[1] F. Boudy, D. Durox, T. Schuller, G. Jomaas, S. Candel, in: GT201022372 (Ed.), ASME Turbo expo, Glasgow, UK.

[2] V. Kornilov, R. Rook, J. ten Thije Boonkkamp, L. de Goey, Combust. Flame 156 (2009) 1957-1970.

[3] T. Poinsot, D. Veynante, Theoretical and Numerical Combustion, R.T. Edwards, 2nd edition, 2005.

[4] T. Lieuwen, V. Yang, in: Prog. in Astronautics and Aeronautics AIAA, volume 210, 2005.

[5] D. G. Crighton, A. P. Dowling, J. E. F. Williams, M. Heckl, F. Leppington, Modern methods in analytical acoustics, Lecture Notes, Springer Verlag, New-York, 1992.

[6] F. E. C. Culick, AIAA Journal 32 (1994) 146-169. 
[7] M. Fleifil, A. M. Annaswamy, Z. A. Ghoneim, A. F. Ghoniem, Combust. Flame 106 (1996) 487-510.

[8] A. P. Dowling, J. Fluid Mech. 394 (1999) 51-72.

[9] C. Pankiewitz, T. Sattelmayer, ASME Journal of Engineering for Gas Turbines and Power 125 (2003) 677-685.

[10] L. Selle, G. Lartigue, T. Poinsot, R. Koch, K.-U. Schildmacher, W. Krebs, B. Prade, P. Kaufmann, D. Veynante, Combust. Flame 137 (2004) 489-505.

[11] L. Crocco, J. American Rocket Society 21 (1951) 163-178.

[12] L. Crocco, in: 12th Symp. (Int.) on Combustion, The Combustion Institute, Pittsburgh, 1969, pp. 85-99.

[13] H. S. Tsien, J. American Rocket Society (1952) 139-143.

[14] T. Lieuwen, J. Prop. Power 19 (2003) 765-781.

[15] A. Giauque, L. Selle, T. Poinsot, H. Buechner, P. Kaufmann, W. Krebs, J. Turb. 6 (2005) 1-20.

[16] S. Hemchandra, T. Lieuwen, Proc. Combust. Inst. 31 (2007) 1427-1434.

[17] S. Ducruix, D. Durox, S. Candel, Proc. Combust. Inst. 28 (2000) 765773.

[18] T. Lieuwen, Y. Neumeier, Proc. Combust. Inst. , 29 (2002) 99-105.

[19] T. Schuller, D. Durox, S. Candel, Combust. Flame 134 (2003) 21-34. 
[20] K. Truffin, T. Poinsot, Combust. Flame 142 (2005) 388-400.

[21] N. Noiray, D. Durox, T. Schuller, S. Candel, J. Fluid Mech. 615 (2008) $139-167$.

[22] D. Durox, T. Schuller, N. Noiray, S. Candel, Proc. Combust. Inst. 32 (2009) 1391-1398.

[23] C. Coats, Z. Chang, P. Williams, Combust. Flame 157 (2010) 10371051.

[24] B. Schuermans, C. Paschereit, P. Monkiewitz, volume AIAA paper 20060549 .

[25] F. Nicoud, L. Benoit, C. Sensiau, AIAA Journal 45 (2007) 426-441.

[26] C. Sensiau, F. Nicoud, T. Poinsot, Int. Journal Aeroacoustics 8 (2009) $57-68$.

[27] R. Kaess, W. Polifke, T. Poinsot, N. Noiray, D. Durox, T. Schuller, S. Candel, in: Proc. of the Summer Program, Center for Turbulence Research, NASA AMES, Stanford University, USA, pp. 289-302, 2008.

[28] H. Wang, C.K. Law, T. Lieuwen, Combust. Flame 156 (2009) 889-895.

[29] J. Donea, A. Huerta, Finite Element Methods for Flow Problems, Wiley, 2003.

[30] O. Colin, M. Rudgyard, J. Comput. Phys. 162 (2000) 338-371.

[31] D. Thevenin, Proc. Combust. Inst. 30 (2004) 629-637. 
[32] R. Sankaran, E. Hawkes, J. Chen, T. Lu, C. K. Law, Proc. Combust. Inst. 31 (2007) 1291-1298.

[33] J. Bell, M. Day, J. Grcar, M. Lijewskia, J. F. Driscoll, S. Filatyev, Proc. Combust. Inst. 31 (2007) 1299-1307.

[34] M. Frenklach, H. Wang, M. Goldenberg, G. P. Smith, D. M. Golden, C. T. Bowman, R. K. Hanson, W. C. Gardiner, V. Lissianki, GRIMech: an optimized detailed chemical reaction mechanism for methane combustion, Technical Report GRI-Report GRI-95/0058, Gas Research Institute, 1995.

[35] T. Poinsot, S. Lele, J. Comput. Phys. 101 (1992) 104-129.

[36] A. Kaufmann, F. Nicoud, T. Poinsot, Combust. Flame 131 (2002) $371-385$.

[37] F. Egolfopoulos, C. K. Law, in: 25th Symp. (Int.) on Combustion, The Combustion Institute, Pittsburgh, 1994, pp. 1341-1347.

[38] M. I. Hassan, K. T. Aung, G. M. Faeth, Combust. Flame 115 (1998) $539-550$.

[39] L. Selle, T. Poinsot, B. Ferret, Combust. Flame 158 (2010) 146-154.

[40] Y. Ogami, H. Kobayashi, JSME Int. J. Series B 48 (2005) 603-609. 


\begin{tabular}{|c|c|c|c|c|c|c|c|c|}
\hline$A_{1}$ & $n_{1}^{C H_{4}}$ & $n_{1}^{O_{2}}$ & $E_{a 1}$ & $A_{2}$ & $n_{2}^{C O}$ & $n_{2}^{O_{2}}$ & $n_{2}^{C O_{2}}$ & $E_{a 2}$ \\
\hline $210^{15}$ & 0.9 & 1.1 & 34500 & $210^{9}$ & 1 & 0.5 & 1 & 12000 \\
\hline
\end{tabular}

Table 1: Rate constants for the 2S-CM2 scheme used in the DNS code: the activation energies are in cal/moles and the preexponential constants in cgs units.

\begin{tabular}{|c|c|c|c|c|c|}
\hline $\mathrm{CH}_{4}$ & $\mathrm{CO}_{2}$ & $\mathrm{CO}$ & $\mathrm{O}_{2}$ & $\mathrm{H}_{2} \mathrm{O}$ & $\mathrm{N}_{2}$ \\
\hline 0.68 & 0.98 & 0.76 & 0.76 & 0.6 & 0.75 \\
\hline
\end{tabular}

Table 2: Schmidt numbers used in the DNS code.

\section{Tables}




\begin{tabular}{cccccc}
\hline Case & $s_{L}(300 \mathrm{~K})(\mathrm{cm} / \mathrm{s})$ & $\alpha($ degrees $)$ & $T_{a}(\mathrm{~K})$ & $T_{d}(\mathrm{~K})$ & $T_{w}(\mathrm{~K})$ \\
\hline$B_{1}$ & 35.8 & 0 & 293 & 430 & 430 \\
$B_{2}$ & $\mathbf{3 2 . 9}$ & 0 & 293 & 430 & 430 \\
$B_{3}$ & $\mathbf{3 8 . 1}$ & 0 & 293 & 430 & 430 \\
$B_{4}$ & 35.8 & 0 & $\mathbf{2 8 3}$ & 430 & 430 \\
$B_{5}$ & 35.8 & 0 & $\mathbf{3 0 3}$ & 430 & 430 \\
$B_{6}$ & 35.8 & 0 & 293 & $\mathbf{2 9 3}$ & $\mathbf{3 8 0}$ \\
$B_{7}$ & 35.8 & 0 & 293 & $\mathbf{2 9 3}$ & 430 \\
$B_{8}$ & 35.8 & 0 & 293 & $\mathbf{2 9 3}$ & $\mathbf{4 8 0}$ \\
$B_{9}$ & 35.8 & $\mathbf{5}$ & 293 & 430 & 430 \\
$B_{10}$ & 35.8 & $\mathbf{1 0}$ & 293 & 430 & 430 \\
\hline
\end{tabular}

Table 3: Computational parameters for sensitivity analysis of FTF for the Boudy configuration. Bold characters indicate changes with respect to $B_{1}$ case. 


\begin{tabular}{cccccc}
\hline Case & $s_{L}(300 \mathrm{~K})(\mathrm{cm} / \mathrm{s})$ & $\alpha$ (degrees) & $T_{a}(\mathrm{~K})$ & $T_{d}(\mathrm{~K})$ & $T_{w}(\mathrm{~K})$ \\
\hline$K_{1}$ & 27.4 & 0 & 293 & 373 & 373 \\
$K_{2}$ & $\mathbf{2 4 . 9}$ & 0 & 293 & 373 & 373 \\
$K_{3}$ & $\mathbf{2 9 . 5}$ & 0 & 293 & 373 & 373 \\
$K_{4}$ & 27.4 & 0 & 283 & 373 & 373 \\
$K_{5}$ & 27.4 & 0 & 303 & 373 & 373 \\
$K_{6}$ & 27.4 & 0 & 293 & $\mathbf{2 9 3}$ & $\mathbf{3 2 3}$ \\
$K_{7}$ & 27.4 & 0 & 293 & $\mathbf{2 9 3}$ & 373 \\
$K_{8}$ & 27.4 & 0 & 293 & $\mathbf{2 9 3}$ & $\mathbf{4 2 3}$ \\
$K_{9}$ & 27.4 & $\mathbf{5}$ & 293 & 373 & 373 \\
$K_{10}$ & 27.4 & $\mathbf{1 0}$ & 293 & 373 & 373 \\
\hline
\end{tabular}

Table 4: Computational parameters for sensitivity analysis of FTF for the Kornilov configuration. Bold characters indicate changes with respect to $K_{1}$ case.

\begin{tabular}{|c|c|c|c|}
\hline Sensitivity & Units & Boudy & Kornilov \\
\hline \hline$\frac{\partial \phi}{\partial s_{L}}$ & $(\mathrm{rad} / \mathrm{m} / \mathrm{s})$ & $\frac{\phi\left(B_{3}\right)-\phi\left(B_{2}\right)}{s_{L}\left(B_{3}\right)-s_{L}\left(B_{2}\right)}$ & $\frac{\phi\left(K_{3}\right)-\phi\left(K_{2}\right)}{s_{L}\left(K_{3}\right)-s_{L}\left(K_{2}\right)}$ \\
$\frac{\partial \phi}{\partial \alpha}$ & $(\mathrm{rad} /$ degrees $)$ & $\frac{1}{2}\left(\frac{\phi\left(B_{9}\right)-\phi\left(B_{1}\right)}{\alpha\left(B_{9}\right)-\alpha\left(B_{1}\right)}+\frac{\phi\left(B_{10}\right)-\phi\left(B_{1}\right)}{\alpha\left(B_{10}\right)-\alpha\left(B_{1}\right)}\right)$ & $\frac{1}{2}\left(\frac{\phi\left(K_{9}\right)-\phi\left(K_{1}\right)}{\alpha\left(K_{9}\right)-\alpha\left(K_{1}\right)}+\frac{\phi\left(K_{10}\right)-\phi\left(K_{1}\right)}{\alpha\left(K_{10}\right)-\alpha\left(K_{1}\right)}\right)$ \\
$\frac{\partial \phi}{\partial T_{a}}$ & $(\mathrm{rad} / \mathrm{K})$ & $\frac{\phi\left(B_{5}\right)-\phi\left(B_{4}\right)}{T_{a}\left(B_{5}\right)-T_{a}\left(B_{4}\right)}$ & $\frac{\phi\left(K_{5}\right)-\phi\left(K_{4}\right)}{T_{a}\left(K_{5}\right)-T_{a}\left(K_{4}\right)}$ \\
$\frac{\partial \phi}{\partial T_{d}}$ & $(\mathrm{rad} / \mathrm{K})$ & $\frac{\phi\left(B_{7}\right)-\phi\left(B_{1}\right)}{T_{d}\left(B_{7}\right)-T_{d}\left(B_{1}\right)}$ & $\frac{\phi\left(K_{7}\right)-\phi\left(K_{1}\right)}{T_{d}\left(K_{7}\right)-T_{d}\left(K_{1}\right)}$ \\
$\frac{\partial \phi}{\partial T_{w}}$ & $(\mathrm{rad} / \mathrm{K})$ & $\frac{\phi\left(B_{8}\right)-\phi\left(B_{6}\right)}{T_{w}\left(B_{8}\right)-T_{w}\left(B_{6}\right)}$ & $\frac{\phi\left(K_{8}\right)-\phi\left(K_{6}\right)}{T_{w}\left(K_{8}\right)-T_{w}\left(K_{6}\right)}$ \\
\hline
\end{tabular}

Table 5: Sensitivity of the phase $\phi$ of the FTF versus computations parameters. 


\begin{tabular}{ccccccc}
\hline & $\bar{V}_{e}(\mathrm{~m} / \mathrm{s})$ & $V_{e}^{M}(\mathrm{~m} / \mathrm{s})$ & $S_{F}\left(\mathrm{~mm}^{2}\right)$ & $L_{F}(\mathrm{~mm})$ & $\overline{s_{L}}(\mathrm{~m} / \mathrm{s})$ & $\bar{T}_{e}(\mathrm{~K})$ \\
\hline$B_{1}$ & 3.48 & 4.95 & 0.85 & 0.62 & 0.38 & 350 \\
$B_{2}$ & 3.48 & 4.95 & 0.91 & 0.64 & 0.35 & 350 \\
$B_{3}$ & 3.48 & 4.95 & 0.80 & 0.61 & 0.40 & 350 \\
$B_{4}$ & 3.51 & 4.96 & 0.88 & 0.62 & 0.37 & 343 \\
$B_{5}$ & 3.46 & 4.95 & 0.81 & 0.62 & 0.39 & 357 \\
$B_{6}$ & 3.28 & 4.60 & 0.91 & 0.67 & 0.32 & 299 \\
$B_{7}$ & 3.29 & 4.58 & 0.91 & 0.64 & 0.32 & 301 \\
$B_{8}$ & 3.30 & 4.56 & 0.90 & 0.61 & 0.32 & 304 \\
$B_{9}$ & 3.48 & 4.95 & 0.86 & 0.59 & 0.37 & 350 \\
$B_{10}$ & 3.48 & 4.95 & 0.86 & 0.60 & 0.37 & 350 \\
\hline
\end{tabular}

Table 6: Effect on uncertain parameters on bulk velocity at the perforation exit $\bar{V}_{e}$, maximum velocity of the exit perforation profile $V_{e}^{M}$, flame surface $S_{F}$, flame lift off $L_{F}$, mean flame speed $\overline{s_{L}}$ and mean temperature at the hole exit $\bar{T}_{e}$ for the different steady Boudy cases $B_{i}$. 


\begin{tabular}{ccccccc}
\hline & $\bar{V}_{e}(\mathrm{~m} / \mathrm{s})$ & $V_{e}^{M}(\mathrm{~m} / \mathrm{s})$ & $S_{F}(\mathrm{~mm})$ & $L_{F}(\mathrm{~mm})$ & $\overline{s_{L}}(\mathrm{~m} / \mathrm{s})$ & $\bar{T}_{e}(\mathrm{~K})$ \\
\hline$K_{1}$ & 1.04 & 1.36 & 4.12 & 0.62 & 0.26 & 317 \\
$K_{2}$ & 1.04 & 1.36 & 4.67 & 0.65 & 0.23 & 317 \\
$K_{3}$ & 1.04 & 1.35 & 3.73 & 0.61 & 0.29 & 317 \\
$K_{4}$ & 1.05 & 1.36 & 4.37 & 0.63 & 0.25 & 309 \\
$K_{5}$ & 1.04 & 1.35 & 3.89 & 0.62 & 0.27 & 324 \\
$K_{6}$ & 1.00 & 1.31 & 4.26 & 0.68 & 0.24 & 295 \\
$K_{7}$ & 1.01 & 1.31 & 4.20 & 0.63 & 0.24 & 298 \\
$K_{8}$ & 1.01 & 1.31 & 4.15 & 0.59 & 0.25 & 301 \\
$K_{9}$ & 1.05 & 1.36 & 4.06 & 0.60 & 0.27 & 316 \\
$K_{10}$ & 1.04 & 1.35 & 4.05 & 0.56 & 0.27 & 317 \\
\hline
\end{tabular}

Table 7: Effect on uncertain parameters on bulk velocity at the perforation exit $\bar{V}_{e}$, maximum velocity of the exit perforation profile $V_{e}^{M}$, flame surface $S_{F}$, flame lift off $L_{F}$, mean flame speed $\overline{s_{L}}$ and mean temperature at the hole exit $\bar{T}_{e}$ for the different steady Kornilov cases $K_{i}$.

\begin{tabular}{|c|c|c|c|}
\hline Sensitivity & Units & Boudy & Kornilov \\
\hline \hline$\frac{\partial \phi}{\partial s_{L}}$ & $(\mathrm{rad} / \mathrm{m} / \mathrm{s})$ & -7.1 & -68.2 \\
$\frac{\partial \phi}{\partial \alpha}$ & $(\mathrm{rad} /$ degrees $)$ & 0.03 & 0.09 \\
$\frac{\partial \phi}{\partial T_{a}}$ & $(\mathrm{rad} / \mathrm{K})$ & -0.01 & -0.05 \\
$\frac{\partial \phi}{\partial T_{d}}$ & $(\mathrm{rad} / \mathrm{K})$ & -0.004 & -0.02 \\
$\frac{\partial \phi}{\partial T_{w}}$ & $(\mathrm{rad} / \mathrm{K})$ & -0.0003 & -0.0014 \\
\hline
\end{tabular}

Table 8: Sensitivity of the phase $\phi$ of the FTF versus computations parameters for a forcing frequency of $500 \mathrm{~Hz}$. 


\begin{tabular}{|l|c|c|}
\hline Absolute error $(\mathrm{rad})$ & Boudy & Kornilov \\
\hline \hline Due to errors on $s_{L}$ & -0.14 & -1.36 \\
Due to errors on $\alpha$ & 0.12 & 0.36 \\
Due to errors on $T_{a}$ & -0.03 & -0.10 \\
Due to errors on $T_{d}$ & -0.18 & -0.96 \\
Due to errors on $T_{w}$ & -0.02 & -0.07 \\
\hline
\end{tabular}

\begin{tabular}{|l|c|c|}
\hline Relative error $(\%)$ & Boudy & Kornilov \\
\hline \hline Due to errors on $s_{L}$ & -4.9 & -9.0 \\
Due to errors on $\alpha$ & 4.2 & 2.4 \\
Due to errors on $T_{a}$ & -0.9 & -0.7 \\
Due to errors on $T_{d}$ & -6.3 & -6.4 \\
Due to errors on $T_{w}$ & -0.6 & -0.5 \\
\hline
\end{tabular}

Table 9: Absolute and relative errors on the phase $\phi$ of the FTF versus computations parameters for a forcing frequency of $500 \mathrm{~Hz}$. Relative errors are based on the phases of $B_{1}$ and $K_{1}$ cases. 


\section{Figures}

\section{List of Figures}

1 Parameters controlling the FTF of a laminar premixed flame. . 36

2 The two laminar flame experiments computed in this work.

Left: the experiment of Boudy et al. [1]. Right: the experiment of Kornilov et al. [2]. . . . . . . . . . . . . . 36

3 CFD models used for the simulation of the Boudy and Kornilov cases. . . . . . . . . . . . . . . . 37

4 Experimental visualization of the stationary flames obtained with the Boudy configuration [1]. . . . . . . . . . . 37

5 Comparison of experimental flame visualizations and DNS reaction rate for the steady flames. Left: direct visualization of the Boudy flame [1] and DNS $B_{1}$. Right: chemiluminescence of $O H^{*}$ of Kornilov flame [2] and DNS $K_{1} \ldots \ldots$. . . . . 38

6 Axial velocity and temperature fields in Boudy DNS $B_{1}$ (Left - obtained with model (a)) and Kornilov DNS $K_{1}$ (Right). Isoline of null axial velocity. . . . . . . . . . . . . . . . . 39

7 Comparison of experimental (symbols) and DNS (solid line) axial velocity on the flames axis. Left: experiment of Boudy [1] with DNS case $B_{1}$. Right: experiment of Kornilov [2] with DNS case $K_{1} \ldots \ldots \ldots \ldots \ldots \ldots \ldots$

8 Comparison of experimental (symbols) and DNS (solid line) axial velocity at $0.7 \mathrm{~mm}$ above the plate: experiment of Boudy [1] with DNS case $B_{1} \ldots \ldots \ldots \ldots$. . . . . . . . . . . . . 40 
9 Comparison of experimental and DNS Flame Transfer Functions: phase $\phi$ (left) and gain (right). Dashed line: Boudy experiment [1], filled circles: Boudy DNS case $B_{1}$, open circles: analytical expression (Eq. 4 with $V_{e}=3.48 \mathrm{~m} / \mathrm{s}, H_{f}=7.5 \mathrm{~mm}$ and $\beta=2$ ). Solid line: Kornilov experiment [2], filled squares: Kornilov DNS case $K_{1}$, open squares: analytical expression (Eq. 4 with $V_{e}=1.04 \mathrm{~m} / \mathrm{s}, H_{f}=5 \mathrm{~mm}$ and $\beta=1$ ). . . . . . 40

10 Effect of the uncertain parameters on the axial velocity along the flame axis for the Boudy case [1]: (a) effect of flame speed $s_{L}$, (b) effect of confinement angle $\alpha$, (c) effect of inlet mixture temperature $T_{a}$, (d) effect of inlet duct temperature $T_{d}$, (e) effect of wall combustor temperature $T_{w} \ldots \ldots \ldots$. . . . . 41

11 Relative errors on the phase $\phi$ of the Kornilov FTF versus computations parameters for several frequencies (left). Mean of relative errors on the phase $\phi$ of the Kornilov FTF over the frequency range $[100,500] \mathrm{Hz}$ (right). . . . . . . . . . . . 42

12 Phase $\phi$ of the $K_{1}$ to $K_{10}$ Kornilov flames versus reduced pulsation $\omega^{*}=\omega r_{p} / \overline{s_{L}}$ pulsated at $200 \mathrm{~Hz}$ (a) and for all frequencies

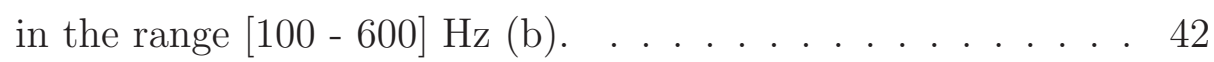




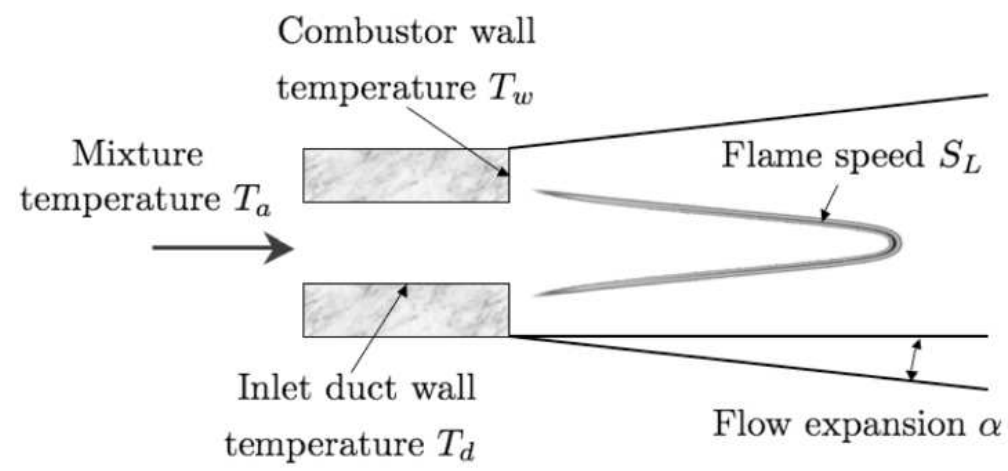

Figure 1: Parameters controlling the FTF of a laminar premixed flame.
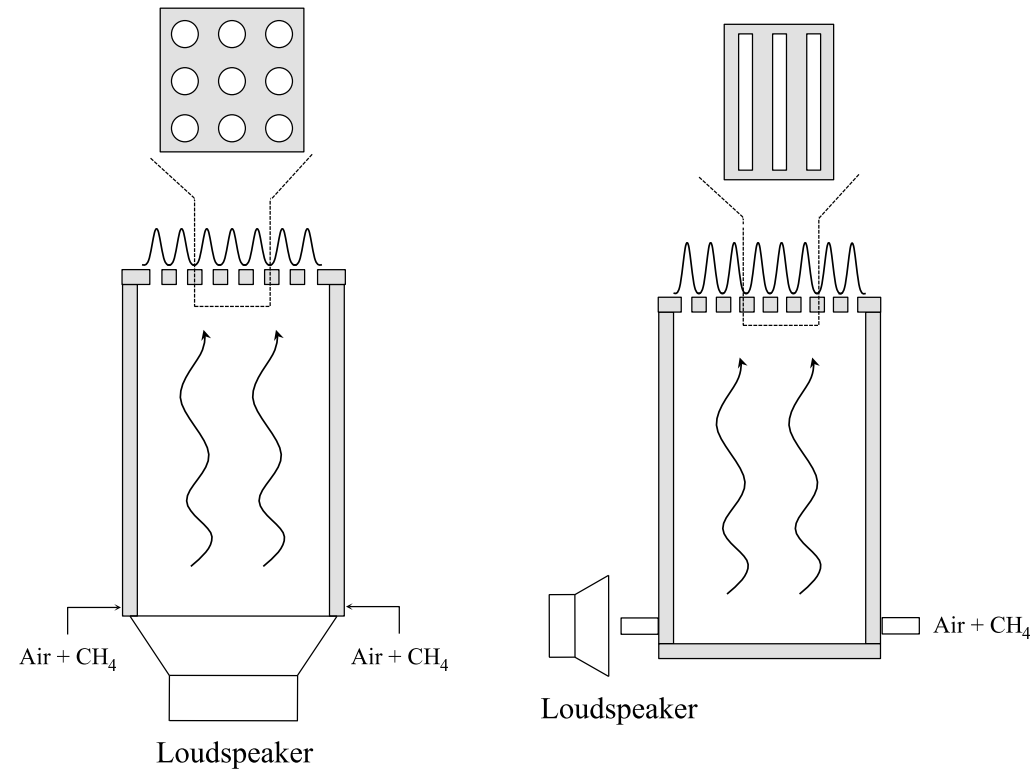

Loudspeaker

Figure 2: The two laminar flame experiments computed in this work. Left: the experiment of Boudy et al. [1]. Right: the experiment of Kornilov et al. [2]. 


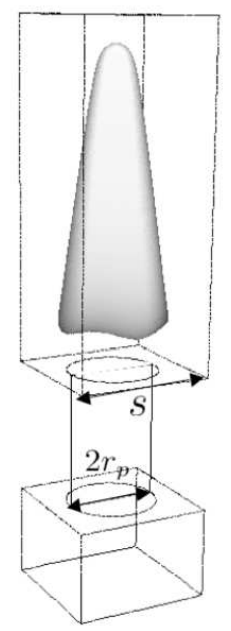

Boudy model (a) Boudy model (b) Kornilov model

Figure 3: CFD models used for the simulation of the Boudy and Kornilov cases.

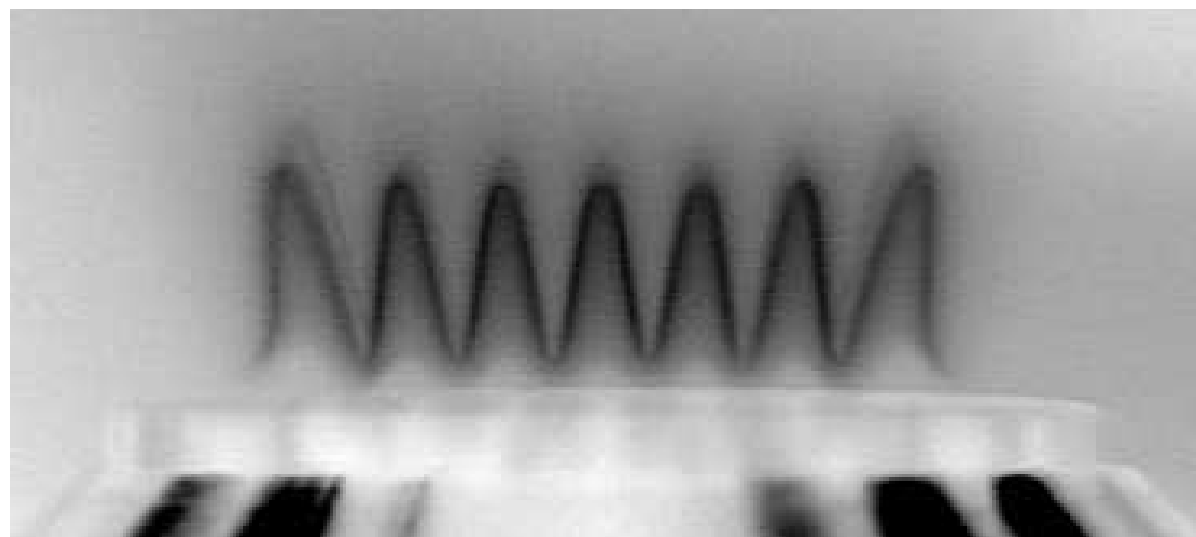

Figure 4: Experimental visualization of the stationary flames obtained with the Boudy configuration [1]. 


\section{EXP DNS}

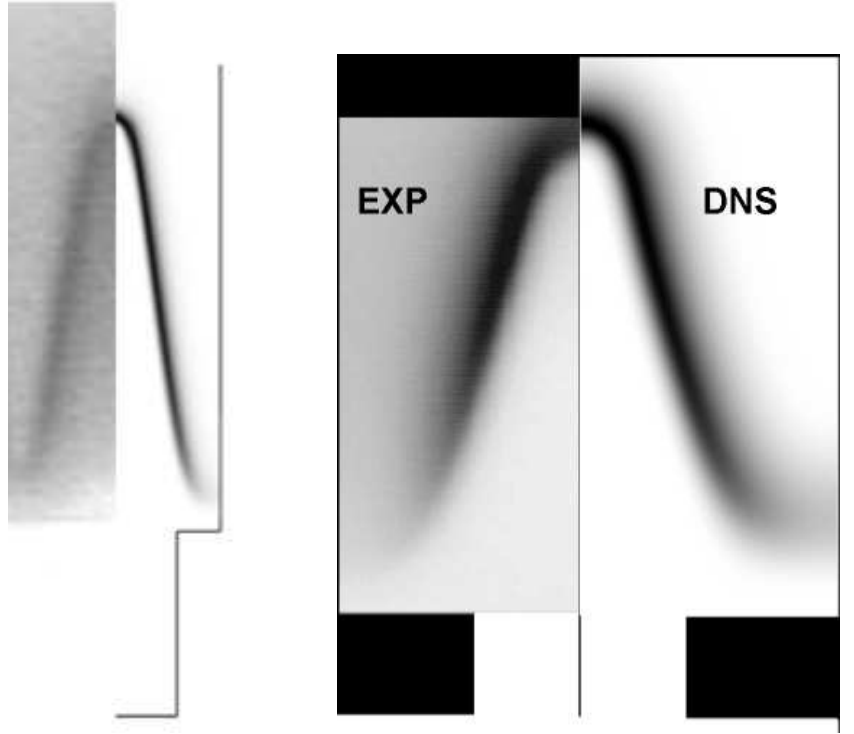

Figure 5: Comparison of experimental flame visualizations and DNS reaction rate for the steady flames. Left: direct visualization of the Boudy flame [1] and DNS $B_{1}$. Right: chemiluminescence of $O H^{*}$ of Kornilov flame [2] and DNS $K_{1}$. 

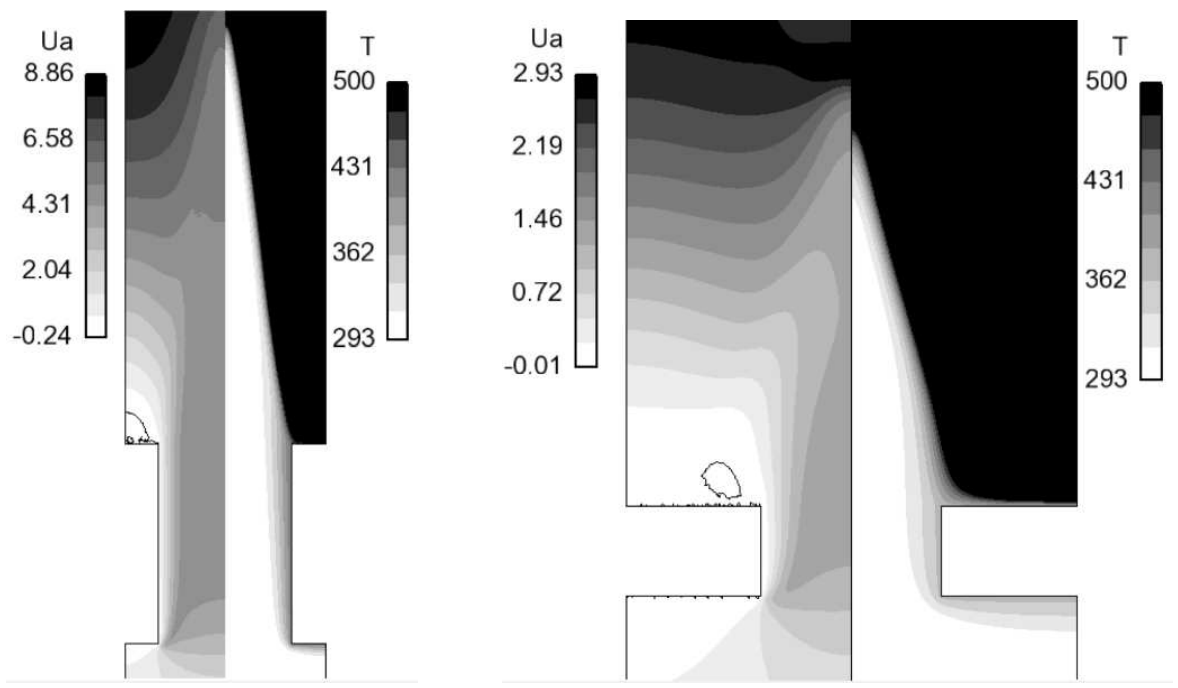

Figure 6: Axial velocity and temperature fields in Boudy DNS $B_{1}$ (Left - obtained with model (a)) and Kornilov DNS $K_{1}$ (Right). Isoline of null axial velocity.
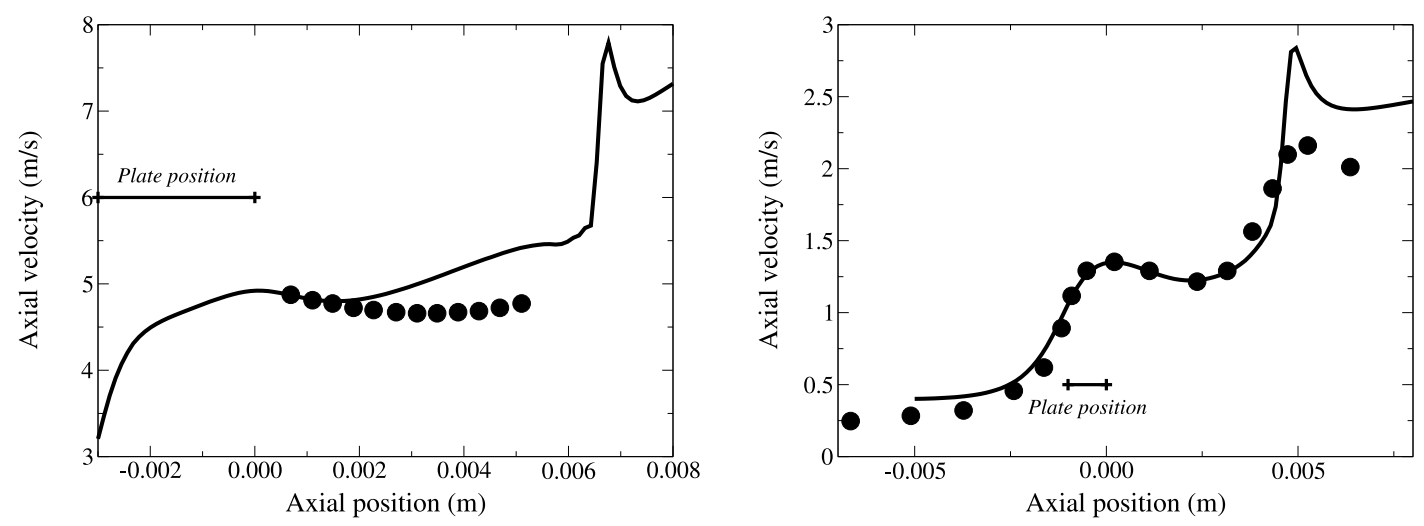

Figure 7: Comparison of experimental (symbols) and DNS (solid line) axial velocity on the flames axis. Left: experiment of Boudy [1] with DNS case $B_{1}$. Right: experiment of Kornilov [2] with DNS case $K_{1}$. 


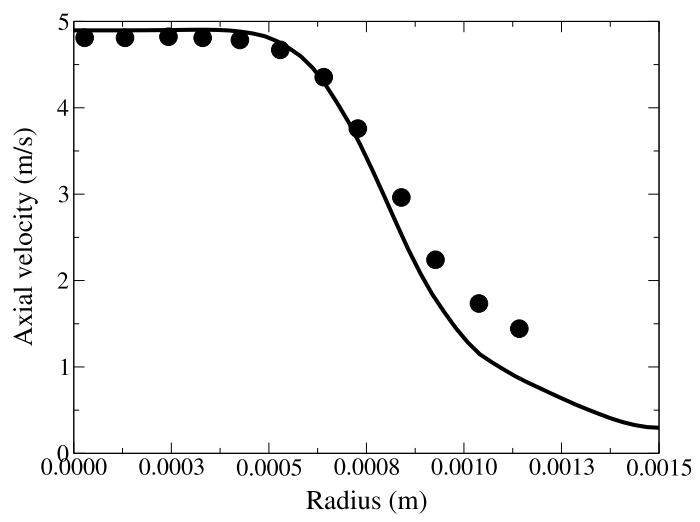

Figure 8: Comparison of experimental (symbols) and DNS (solid line) axial velocity at $0.7 \mathrm{~mm}$ above the plate: experiment of Boudy [1] with DNS case $B_{1}$.
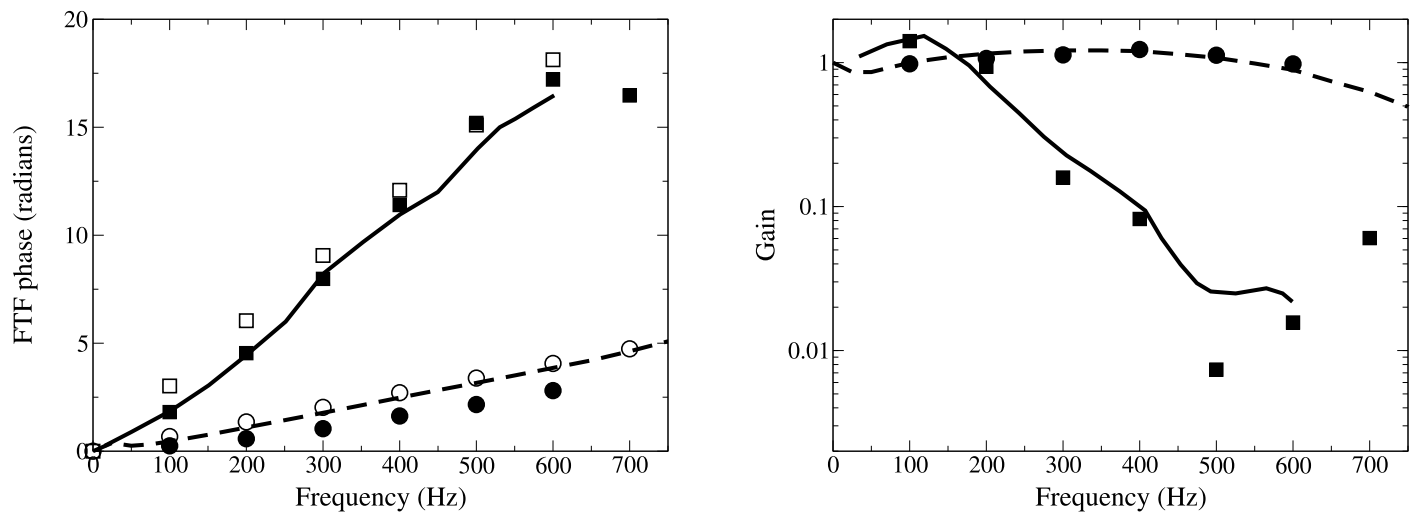

Figure 9: Comparison of experimental and DNS Flame Transfer Functions: phase $\phi$ (left) and gain (right). Dashed line: Boudy experiment [1], filled circles: Boudy DNS case $B_{1}$, open circles: analytical expression (Eq. 4 with $V_{e}=3.48 \mathrm{~m} / \mathrm{s}, H_{f}=7.5 \mathrm{~mm}$ and $\beta=2$ ). Solid line: Kornilov experiment [2], filled squares: Kornilov DNS case $K_{1}$, open squares: analytical expression (Eq. 4 with $V_{e}=1.04 \mathrm{~m} / \mathrm{s}, H_{f}=5 \mathrm{~mm}$ and $\beta=1$ ). 


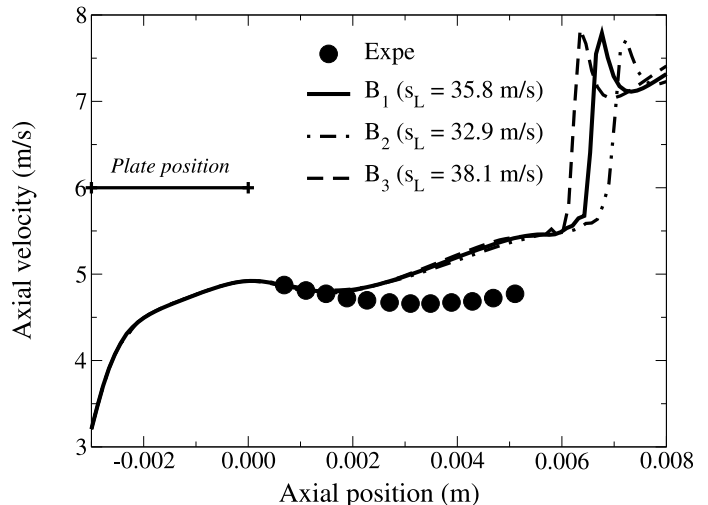

(a)

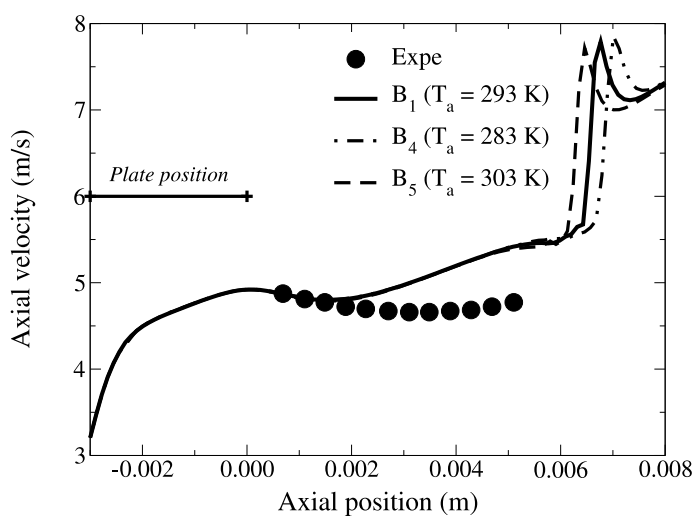

(c)

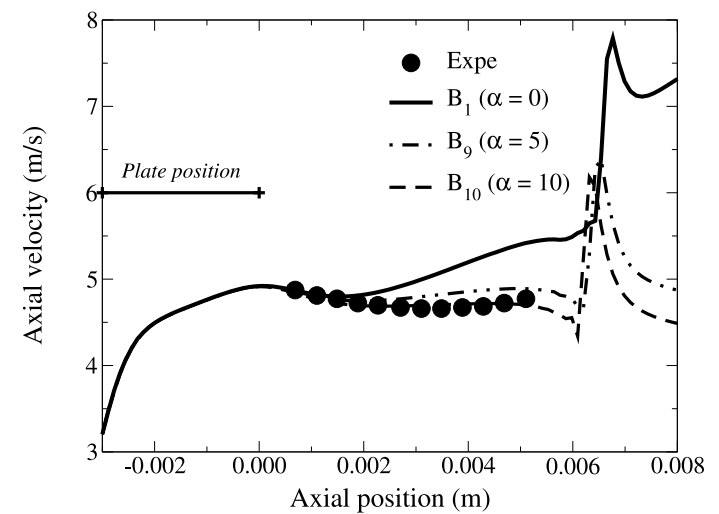

(b)

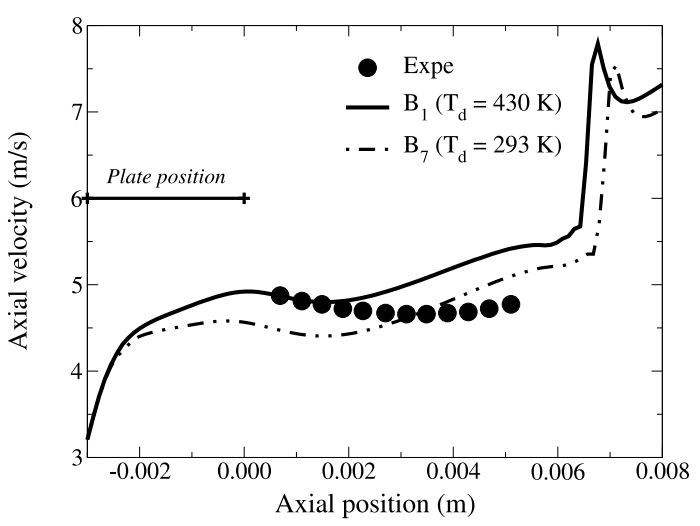

(d)

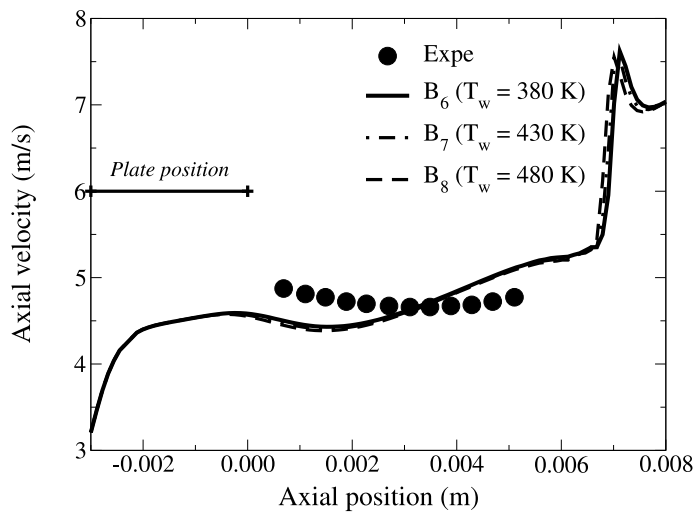

(e)

Figure 10: Effect of the uncertain parameters on the axial velocity along the flame axis for the Boudy case [1]: (a) effect of flame speed $s_{L}$, (b) effect of confinement angle $\alpha$, (c) effect of inlet mixture temperature $T_{a}$, (d) effect of inlet duct temperature $T_{d}$, (e) effect of wall combustor temperature $T_{w}$. 

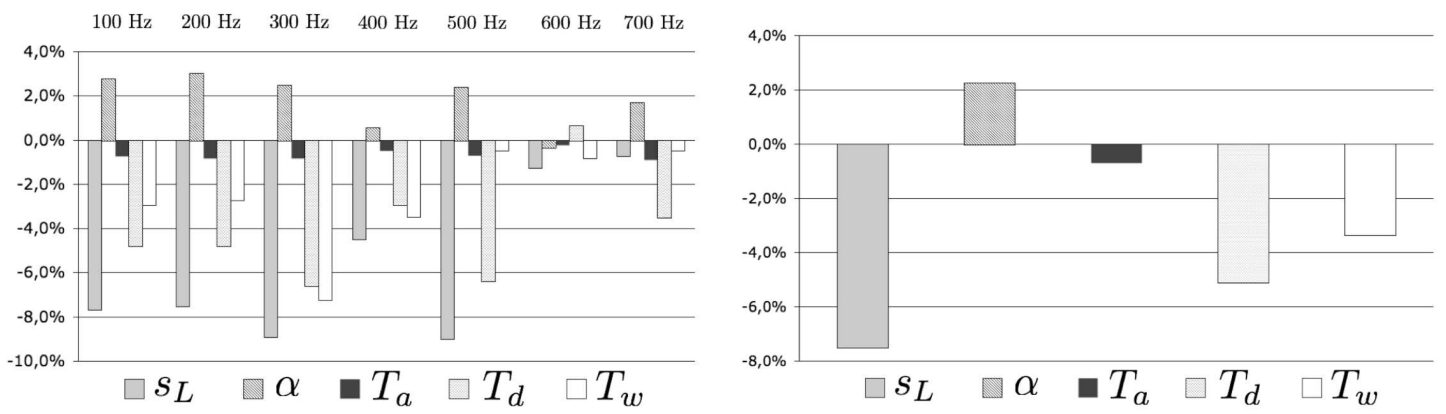

Figure 11: Relative errors on the phase $\phi$ of the Kornilov FTF versus computations parameters for several frequencies (left). Mean of relative errors on the phase $\phi$ of the Kornilov FTF over the frequency range $[100,500] \mathrm{Hz}$ (right).

(a)
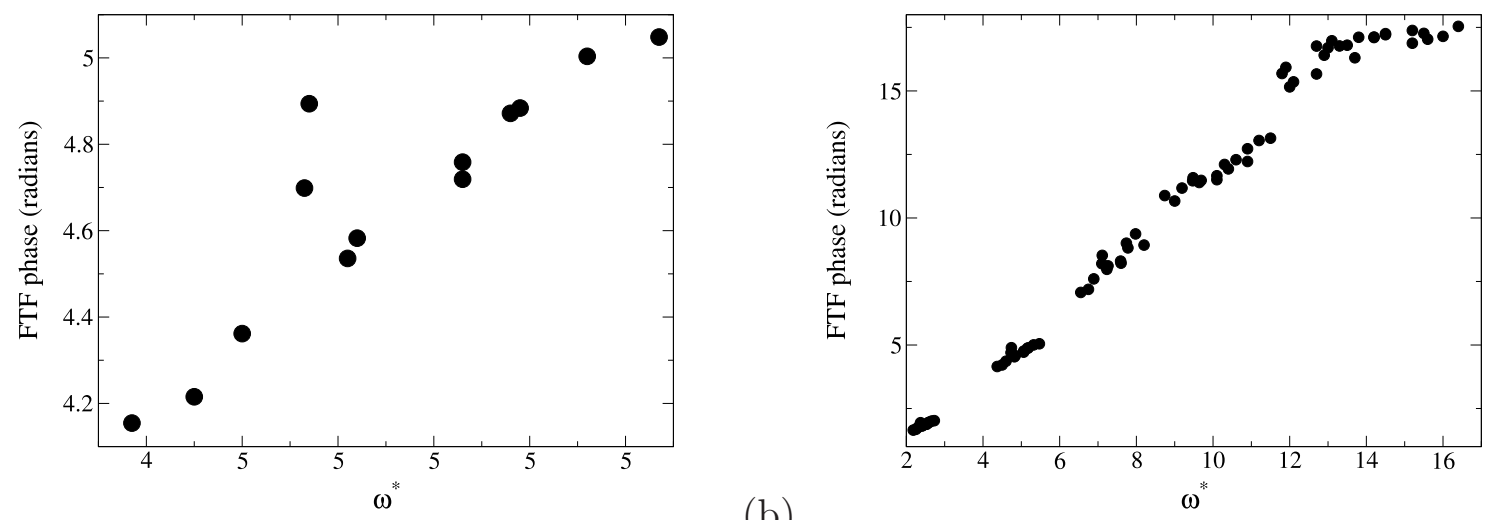

Figure 12: Phase $\phi$ of the $K_{1}$ to $K_{10}$ Kornilov flames versus reduced pulsation $\omega^{*}=\omega r_{p} / \overline{s_{L}}$ pulsated at $200 \mathrm{~Hz}$ (a) and for all frequencies in the range [100 - 600] $\mathrm{Hz}(\mathrm{b})$. 